\title{
Healthy Living for Elders: Food Can Affect Your Medicines ${ }^{1}$
}

IFAS EXTENSION

Paulina Wittkowsky ${ }^{2}$

Food can affect the way prescription and over-the-counter medicines work. This can cause unwanted effects. When taking certain medicines, some foods should be avoided.

\section{ALCOHOL}

Drinking alcohol when you are taking certain medicines can be very dangerous. Some drugs that are affected by alcohol are acetaminophen (such as Tylenol ${ }^{\mathrm{TM}}$ ), antihistamines (such as Benadryl ${ }^{\mathrm{TM}}$ ), and ibuprofen (such as Motrin ${ }^{\mathrm{TM}}$ ).

\section{Always ask your doctor or} pharmacist if alcohol can affect the medicine you are taking!

\section{MILK}

Some antibiotics, like tetracycline, should not be taken with milk.

\section{VEGETABLES}

Vegetables that contain vitamin $\mathrm{K}$, such as spinach, kale, and Brussels sprouts, can reduce the effectiveness of blood thinners (such as Coumadin ${ }^{\mathrm{TM}}$ ).

\section{P TAKE WITH FOOD \\ R}

\section{GRAPEFRUIT JUICE}

Grapefruit juice increases the effect of some medicines. It is best not to take medicine with grapefruit juice.

\section{Drink grapefruit juice at least two} hours after or before you take your medicine.
Certain medicines should be taken with food. This can help prevent stomach irritation. Examples of these medicines are ibuprofen (such as Motrin ${ }^{\mathrm{TM}}$ ) and certain diuretics (such as Aldactone ${ }^{\mathrm{TM}}$ ).

Ask your doctor or pharmacist for more information on how food can affect your medicines.

1. This is document FCS 8622-ENG, one in a series of the Department of Family, Youth and Community Sciences, Florida Cooperative Extension Service, Institute of Food and Agricultural Sciences, University of Florida, Gainesville, FL 32611. Publication date: March 2004. This leaflet was developed with funding from the Florida Department of Elder Affairs in partnership with state, county, and local agencies. Please visit the EDIS Web site at http://edis.ifas.ufl.edu

2. Paulina Wittkowsky, MS, RD, former education assistant, Department of Family, Youth and Community Sciences, Institute of Food and Agricultural Sciences, University of Florida, Gainesville, FL 32611. Reviewed by Linda B. Bobroff, PhD, RD, LD/N, professor, University of Florida.

The use of trade names in this publication is solely for the purpose of providing specific information. UF/IFAS does not guarantee or warranty the products named, and references to them in this publication does not signify our approval to the exclusion of other products of suitable composition. 